\title{
OUTCOME OF PRIMARY PERCUTANEOUS CORONARY INTERVENTION IN PATIENTS WITH ACUTE ST-SEGMENT ELEVATION MYOCARDIAL INFARCTION ARRIVING IN ARMY CARDIAC CENTER LAHORE
}

\author{
Khurram Shahzad, Jahanzab Ali, Ayaz Ahmad, Ahmad Usman, Amna Rashdi, Faisal Shafiq \\ Army Cardiac Center Lahore/National University of Medical Sciences (NUMS) Pakistan
}

\begin{abstract}
Objective: To evaluate the feasibility and outcomes of primary percutaneous coronary intervention (PCI) as a mode of treatment in acute ST-segment elevation myocardial infarction (STEMI).

Study Design: Descriptive cross sectional study.

Place and Duration of Study: The study was conducted in Army Cardiac Center Lahore, from Nov 2019 to Feb 2020.

Methodology: All patients diagnosed as acute ST-segment elevation myocardial infarction during the study period were offered primary percutaneous coronary intervention among treatment options. Patients who chose primary percutaneous coronary intervention were included in the study. Informed consent was taken. Patient demographics, risk factors, time variables, procedural characteristics and in-hospital adverse events were evaluated.

Results: On admission, Out of 50, 30 (60\%) of the patients were current smokers, 25 (50\%) were hypertensive, $22(44 \%)$ were diabetic, and $1(2 \%)$ had cardiogenic shock. The mean time from symptom onset to hospital arrival was 5 hours and the mean door-to-balloon time was 34 minutes. Culprit coronary artery was the left anterior descending artery (LAD) in 56\% cases and multi-vessel disease was present in $38 \%$ cases. Primary percutaneous coronary intervention involved balloon dilatation $(2 \%)$ and stent implantation $(98 \%)$. The incidence of postprocedural angiographic no-reflow was $0 \%$. All-cause mortality was $1 \%$.

Conclusion: This study has shown efficiency, feasibility and safety in performing of primary percutaneous coronary intervention with excellent outcomes in Army Cardiac Center Lahore. In order to further improve its outcomes, our goal should be to decrease reperfusion time which can be achieved by reducing patient delay, increasing public awareness and improving the management of first medical contact.
\end{abstract}

Keywords: Primary percutaneous coronary intervention, STEMI, Trans-radial.

This is an Open Access article distributed under the terms of the Creative Commons Attribution License (http://creativecommons.org/licenses/by/4.0), which permits unrestricted use, distribution, and reproduction in any medium, provided the original work is properly cited.

\section{INTRODUCTION}

Acute STEMI is the worst presentation of coronary artery disease (CAD) with very high mortality and morbidity ${ }^{1}$. Patient with persistent ST-segment elevation is a candidate for reperfusion therapy (either pharmacologic or catheter based) to restore blood flow in occluded coronary artery. Primary PCI refers to an intervention of the occluded infarct related coronary artery within 12 hours of symptoms onset, without prior fibrinolytic therapy ${ }^{2}$. Primary PCI is an effective and preferable mode of emergency revascularization in patients with acute STEMI. In current era, evidence suggests that revascularization with

Correspondence: Dr Khurram Shahzad, Department of Cardiology, Army Cardiac Center Lahore Pakistan primary PCI results in more favorable outcomes as compared to thrombolysis ${ }^{3}$. It results in early and more persistent reperfusion with less complications as compared to thrombolysis4. Moreover, it significantly decreases re-infarction, mortality and stroke rates ${ }^{5}$. This fact is equally true for acute STEMI patients initially received in PCI centers and for patients shiftedto PCI centers from non-PCI centers ${ }^{6}$. But the later requires development of networks in the region between primary PCI centers and non-PCI centers and availability of an efficient ambulance service. The goal of these networks should be to provide standard treatment twenty four hours a day, seven days a week (24/7) for all acute STEMI patients without delays, in order to have better clinical outcomes. In spite of all these facts, 
primary PCI has not yet been chosen as a first line treatment in most of the developing countries including Pakistan especially in their public sector hospitals. It is mainly because of high procedural cost, less government resources and inadequate hospital funding. This is the reason that there is not much data available on primary PCI from the developing countries including Pakistan. Primary PCI is the gold standard treatment for patients with acute STEMI if experienced interventional cardiologists with wellequipped catheterization laboratory along with surgical backup are available and if the procedure can be done preferably within 90 minutes of patient's first medical contact ${ }^{7}$. Now primary PCIs are being done routinely at Army Cardiac Center Lahore as a first line mode of treatment for acute STEMI patients. In this study, we evaluated outcomesof primary PCI in first 50 patients with acute STEMI.

\section{METHODOLOGY}

\section{Study Population}

This study was done at Army Cardiac Center Lahore from November 2019 to February 2020. All patients diagnosed with acute STEMI, after thorough counselling, were offered both primary PCI and thrombolysis as treatment options and patients who opted for primary PCI were included in the study after taking Informed consent. Other inclusion criteria were: (1) chest pain suggestive of ischemic heart disease with (2) ST segment elevation of $>1 \mathrm{~mm}$ in two or more contiguous limb leads or ST segment elevation of $>2$ $\mathrm{mm}$ in two or more contiguous precordial leads and (3) admission within 12 hours of onset of chest pain. Exclusion criteria were: (1) patients who already received thrombolytic therapy within 24 hours of hospital admission, (2) patients who presented after 12 hours of symptom-onset and were asymptomatic, (3) patients who were diagnosed as case of Non ST-segment Elevation Myocardial Infarction (NSTEMI), (4) patients with known pregnancy and (5) patients who chose thrombolysis as mode of treatment.

\section{Interventional Procedure And Adjunctive Medications}

All patients received 100 units $/ \mathrm{kg}$ intravenous bolus of unfractionated heparin, $300 \mathrm{mg}$ aspirin and 600mg clopidogrel. Glycoprotein IIb/ IIIa inhibitor (tirofibran) as intracoronary bolus $(10 \mu \mathrm{g} / \mathrm{kg})$ followed by intravenous infu-sion $(0.15 \mu \mathrm{g} / \mathrm{kg} / \mathrm{min})$ was used according to operator's discretion. All the procedures were done by getting radial artery access. Culprit coronary artery was engaged with an appropriate sized guiding catheter and the lesion was crossed with suitable guide wire. A variety of balloons were used and stent implantation was done according to standard methods. We used drug-eluting stents (DES) in all the cases to minimize the risk for stent restenosis. In case of multi-vessel coronary artery disease, primary PCI was limited to infarct related coronary artery. During procedures, nonionic contrast media was used. Aspirin, clopidogrel, beta-adrenergic blockers, angiotensin converting enzyme inhibitors, diuretics and statins were used according to guidelines, if not contraindicated.

\section{Data Collection And Statistical Analysis}

The data of the following variables was obtained and analyzed: age, gender, diabetes, hypertension, smoking, dyslipidemia, prior history of coronary artery bypass grafting (CABG) or $\mathrm{PCI}$, requirement of temporary pacemaker (TPM) or intra-aotic balloon pump (IABP), procedural details (number of diseased arteries, culprit coronary artery, type of stents, use of glycoprotein (GP) IIb/IIIa inhibitors, thrombolysis in myocardial infarction [TIMI] flow grade) and electrocardiogram (ECG). There were two Timing variables recorded and documented. Door time was defined as the time from pain onset to hospital arrival. Door-to-balloon time was defined as the timefrom hospital arrival to first ballooning. ST-segment resolution (on 12- lead ECGs) and TIMI flow were visually assessed and documented by two independent observers both before and after primary PCI. Successfulprimary PCI was defined as the reperfusion of culprit 
coronary artery with TIMI III flow. In-hospital adverse events (re-infarction, urgent CABG, death, bleeding and stroke) were assessed. All statistical calculations were performed using SPSS version 20 software.

\section{RESULTS}

A total of 50 patients underwent primary PCI during the study period. Demographic and clinical characteristics of patients are presented in table-I. The mean age of the patients in study

Table-I: Demographic and clinical characteristics $(\mathrm{n}=50)$.

\begin{tabular}{|c|c|}
\hline & n (\%) \\
\hline \multicolumn{2}{|l|}{ Gender } \\
\hline Male & $44(88 \%)$ \\
\hline Female & $06(12 \%)$ \\
\hline \multicolumn{2}{|l|}{ Past Medical History } \\
\hline Diabetes Mellitus & $22(44 \%)$ \\
\hline Hypertension & $25(50 \%)$ \\
\hline Smoker & $30(60 \%)$ \\
\hline Dyslipidemia & $09(18 \%)$ \\
\hline Family history of CAD & $04(08 \%)$ \\
\hline Past history of CAD & $11(22 \%)$ \\
\hline History of stroke & $01(02 \%)$ \\
\hline Renal insufficiency & $02(04 \%)$ \\
\hline \multicolumn{2}{|l|}{ Killip Class } \\
\hline I & $38(76 \%)$ \\
\hline II & $11(22 \%)$ \\
\hline III & $01(02 \%)$ \\
\hline \multicolumn{2}{|l|}{ Location of STEMI } \\
\hline Anterior STEMI & $27(54 \%)$ \\
\hline Inferior STEMI & $20(40 \%)$ \\
\hline Lateral STEMI & $03(06 \%)$ \\
\hline Cardiogenic shock on admission & $01(02 \%)$ \\
\hline
\end{tabular}

sample was 52 years with range of 31 years to 72 years. The mean door time was 05 hours while door to balloon time was 34 minutes. The most common cardiac risk factor was smoking habits and it was present in $30(60 \%)$ patients. Cardiogenic shock was present in only 01 (2\%) patient on admission. The most common acute STEMI was anterior comprising $54 \%$ of all cases followed by acute inferior STEMI with $40 \%$ of all cases.

The angiographic and procedural findings are presented in Table-II. In all the cases (100\%), vascular access was obtained via trans-radial approach. Left anterior descending artery (LAD) was the most common among infarct related

Table-II: Angiographic and Procedural Findings $(n=50)$.

\begin{tabular}{|c|c|}
\hline & n (\%) \\
\hline \multicolumn{2}{|l|}{ Vascular Access } \\
\hline Trans-Radial & $50(100 \%)$ \\
\hline Trans-Femoral & $0(0 \%)$ \\
\hline \multicolumn{2}{|l|}{ Culprit Vessel } \\
\hline Left anterior descending artery (LAD) & $28(56 \%)$ \\
\hline Right coronary artery (RCA) & $14(28 \%)$ \\
\hline Left circumflex artery (LCX) & $08(16 \%)$ \\
\hline Single vessel CAD & $31(62 \%)$ \\
\hline Multi vessel CAD & $19(38 \%)$ \\
\hline \multicolumn{2}{|l|}{ TIMI Flow } \\
\hline Pre PCI & - \\
\hline 0 & - \\
\hline I & $41(82 \%)$ \\
\hline II & $08(16 \%)$ \\
\hline Post PCI & $01(02 \%)$ \\
\hline 0 & - \\
\hline $\mathrm{I}$ & - \\
\hline II & - \\
\hline III & $50(100 \%)$ \\
\hline \multicolumn{2}{|l|}{ Method of Reperfusion } \\
\hline Balloon angioplasty & $01(02 \%)$ \\
\hline Stenting with predilatation & $39(78 \%)$ \\
\hline Direct stenting & $10(20 \%)$ \\
\hline Visible thrombus & $28(56 \%)$ \\
\hline Thrombus aspiration & $02(04 \%)$ \\
\hline GpIIb/IIIa inhibitor use & $50(100 \%)$ \\
\hline \multicolumn{2}{|l|}{ Type of Stent } \\
\hline Bare metal stents (BMS) & $0(0 \%)$ \\
\hline Drug eluting stents (DES) & $49(98 \%)$ \\
\hline \multicolumn{2}{|l|}{ Number of Stents Implanted } \\
\hline 1 & $48(96 \%)$ \\
\hline 2 & $01(02 \%)$ \\
\hline Dysrhythmias & - \\
\hline Heart block & - \\
\hline I/II degree & $02(04 \%)$ \\
\hline III degree & $03(06 \%)$ \\
\hline Idioventricular tachycardia & $07(14 \%)$ \\
\hline Ventricular tachycardia & $02(04 \%)$ \\
\hline Ventricular fibrillation & $0(0 \%)$ \\
\hline Use of temporary pacemaker & $03(06 \%)$ \\
\hline DC Cardioversion & $02(04 \%)$ \\
\hline
\end{tabular}

arteries (56\%), followed by right coronary artery (28\%). Multi-vessel disease was present in 19 (38\%) patients. Post PCI TIMI flow was III in all 
the patients $(100 \%)$. All stents used were drug eluting stents (DES). Stenting of culprit coronary artery was done in 49 patients (98\%); out of which $20 \%$ was direct stenting.

Major In-hospital events are shown in TableIII. Only one patient ( $2 \%)$ after primary PCI died during the hospital admission because of fatal

Table-III: In-hospital Events $(\mathrm{n}=50)$.

\begin{tabular}{l|c}
\hline & n (\%) \\
\hline Death on table & - \\
\hline In-hospital death & $1(2 \%)$ \\
\hline In-hospital CABG & - \\
\hline Stent thrombosis & - \\
\hline Contrast Induced Nephropathy & $01(02 \%)$ \\
\hline \multicolumn{2}{|l}{ Bleeding Complications } \\
\hline Major & $01(02 \%)$ \\
Minor & $06(12 \%)$ \\
Heart failure & $01(02 \%)$ \\
\hline Arrhythmic Complications & \\
\hline Ventricular fibrillation & $01(02 \%)$ \\
Ventricular tachycardia & $02(04 \%)$ \\
High degree AV block & $03(06 \%)$ \\
New onset atrial fibrillation & - \\
\hline
\end{tabular}

arrhythmias (ventricular fibrillation) and 1 patient $(2 \%)$ had transient contrast induced nephropathy. Major bleeding complications occurred in 1 patient $(2 \%)$.

\section{DISCUSSION}

In this study, we shared our initial experience of primary PCI in 50 patients with STEMI and showed outcomes and results of this procedure. We assessed demographic, angiographic, and procedural characteristics of the primary $\mathrm{PCI}$ patients along with major in-hospital cardiovascular events. It is now well established by many randomized clinical trials that primary PCI is more effective and safe treatment as compared to fibrinolysis in patients with STEMI2,8. Primary PCI is the first line treatment within 90 minutes of hospital admission in patients with STEMI according to both AHA and ESC guidelines ${ }^{2,9}$. Therefore primary PCI is now a routine procedure in our center and has been done 24 hours/ 7 days from the last few months.

The most important determinant of myocardial salvage and mortality in STEMI patients is the total ischemic time ${ }^{10}$. It is the time from symptoms onset to the initiation of reperfusion and it should be as short as possible to get maximum benefit out of primary PCI as emphasized by Tarantini et al study ${ }^{11}$. In this study, mean pain to balloon time was $90 \pm 40 \mathrm{~min}, 110 \pm 107 \mathrm{~min}$, and $137 \pm 97 \mathrm{~min}$ in patients without severe microvascular obstruction (SMO) and myocardial transmural necrosis (TN), with $\mathrm{TN}$ but without $\mathrm{SMO}$, or with both SMO and TN, respectively $(p=0.001)$. This study showed that the risk of TN and SMO increases in STEMI patients with the duration of the total ischemic time. Thus, the amount of salvageable myocardium is indirectly proportional to total ischemic time which leads to the generation of concept of "time is muscle". Xavier et al study determined various factors responsible for the prolongation of the total ischemic time e.g. financial difficulties, lack of awareness, inaccurate diagnosis and paucity of transport facilities ${ }^{12}$.

In our study, the mean door to balloon time was 34 minutes. This shorter door toballoon time was mainly because of quick diagnosis in our emergency department, nearby location of catheterization laboratory, easy and quick transport to catheterization laboratory and 24 hours availability of an expert interventional cardiologist. McNamara et al13 determined a very close association between door to balloon time and inhospital mortality. Every 15 minutes reduction in treatment time between 150 and 90 minutes resulted in a reduction of 6.3 mortalities in 1000 deaths.

Factors that affect the mortality of STEMI are age, mode of treatment, time delay to treatment, Killip class, history of prior ischemic heart disease, renal failure, diabetes mellitus, number of diseased vessels and ejection fraction. In our study, the in-hospital mortality was $2 \%$ that was because of fatal arrhythmias and cardiogenic shock. In-hospital mortality after primary PCI differs from center to center; from $3.2 \% 14,4.2 \% 15$, $4.4 \% 16$. The major reasons for very low in-hospital mortality after primary PCI in our center are prompt STEMI diagnosis, early administration of 
antiplatelets and anticoagulants, short door to balloon time, well equipped catheterization laboratory and availability of experienced interventional cardiologists.

Incidence of minor bleeding was $6(12 \%)$ and major bleeding was 1 (2\%). Trans-radial approach for vascular access is the recommended approach to decrease the risk of bleeding 17 and this was the main reason for low incidence of bleeding in our patients. Other factors responsible for decrease bleeding complications arethe use of smallerdiameter cannulation, controlled anticoagulation regimens, early sheath removal and increased experience of interventional cardiologists ${ }^{18}$.

The most feared complication of PCI is stent thrombosis due to its high mortality and morbidity. The incidence of early stent thrombosis is $1.5 \%$ as documented in studies and its rate is higher in patients with STEMI compared to elective procedures, as stent placement during acute STEMI is a risk factor for stent thrombosis ${ }^{19,20}$. There was not a single case of in-hospital stent thrombosis in our study. This was probably because of the use of DES and effective use of antiplatelets and anticoagulants.

The no-reflow phenomenon is a big problem in STEMI patients undergoing primary PCI and is an independent factor of poor prognosis ${ }^{21}$. Noreflow is an angiographic phenomenon defined as slow flow in the culprit artery (TIMI flow 0-1) and absence of contrast uptake "blush" by the subtended myocardium, resulting in potential mismatch between coronary revascularization and myocardial perfusion in STEMI. There are high short- and long-term mortality and morbidity rates associated with no-reflow. GUSTO-IIb trial showed that 30 -day mortality rate was $1.6 \%$ in patients with TIMI 3 flow, $19.9 \%$ in patients with TIMI 2 flow, and 20\% in patients with TIMI $0-1$ flow $^{22}$. There was no case with angiographic no-reflow in our study.

\section{CONCLUSION}

This study has shown efficiency, feasibility and safety in performing of primary PCI with excellent outcomes in Army Cardiac Center
Lahore. In order to further improve its outcomes, our goal should be to decrease reperfusion time which can be achieved by reducing patient delay, increasing public awareness and improving the management of first medical contact.

\section{CONFLICT OF INTEREST}

This study has no conflict of interest to be declared by any author.

\section{REFERENCES}

1. Roger VL, Go AS, Lloyd-Jones DM, Benjamin EJ, Berry JD, Borden WB, et al. Executive summary: heart disease and stroke statistics - 2012 update: A report from the American Heart Association. Circulation 2012; 125(1): 188-97.

2. Steg G, James S, Atar D, Badano L, Bldmstrom-Lundqvist C, Di Mario $C$, et al. Management of acute myocardial infarction in patients presenting with persistent ST-segment elevation: the Task Force on the Management of ST-Segment Elevation Acute Myocardial Infarction of the European Society of Cardiology. Eur Heart J 2012; 33(1): 2569-619.

3. Itoh T, Fukami K, Suzuki T, Kimura T, Kanaya Y, Orii M, et al. Comparison of long-term prognostic evaluation between preintervention thrombolysis and primary coronary intervention: a prospective randomized trial: five-year results of the important study. Circ J 2010; 74(8): 1625-34.

4. Keeley EC, Boura JA, Grines CL. Primary angioplasty vs. intravenous thrombolytic therapy for acute myocardial infarction: a quantitative review of 23 randomised trials. Lancet 2003; 361(1): 13-20.

5. Massel D, Teefy PJ. Review: Transfer for PCI reduces 30-day mortality more than on-site thrombolysis in STEMI. Ann Intern Med 2009; 150(8): JC4-4.

6. Wildimsky P, Budesimsky T, Vorac D, Groch L, Zelizko M, Aschermann $\mathrm{M}$, et al. Long distance transport for primary angioplasty vs. immediate thrombolysis in acute myocardial infarction: final results of the randomized national multicentre trial PRAGUE-2. Eur Heart J 2003; 24: 94-104.

7. Cannon CP. Evolving management of ST-segment elevation myocardial infarction: update on recent data. Am J Cardiol 2006; 98(1): 10-21.

8. Andersen HR, Nielsen TT, Rasmussen K, Thuesen L, Kelbaek H, et al. A comparison of coronary angioplasty with fibrinolytic therapy in acute myocardial infarction. N Engl J Med 2003; 349: 733-42.

9. O'Gara P, Kushner F, Ascheim D, Casey D. ACCF/AHA Guideline for the Management of ST-Elevation Myocardial Infarction; a report of the american college of cardiology foundation/ american heart association task force on practice guidelines. Circulation 2013; 127: 01-10.

10. De Luca G, Suryapranata H, Ottervanger JP, Antman EM. Time delay to treatment and mortality in primary angioplasty for acute myocardial infarction: every minute of delay counts. Circulation 2004; 109: 1223-25.

11. Tarantini G, Cacciavillani L, Corbetti F. Duration of ischemia is a major determinant of transmurality and severe microvascular obstruction after primary angioplasty: a study performed with contrast enhanced magnetic resonance. J Am Coll Cardiol 2005; 46(1): 1229-35.

12. Xavier D, Pais P, Devereaux PJ. CREATE Registry Investigators. Treatment and outcomes of acute coronary syndromes in India 
(CREATE): a prospective analysis of registry data. Lancet 2008; 371: 1435-42.

13. McNamara RL, Wang Y, Herrin J, Curtis JP, Bradley EH, Magid DJ, et al. Effect of door- to -balloon time on mortality in patients with ST- segment elevation myocardial infarction. J Am Coll Cardiol 2006; 47: 2180-86.

14. Kumbhani DJ, Cannon CP, Fonarow GC, Liang L, Askari AT, Peacock WF. Association of hospital primary angioplasty volume in ST-segment elevation myocardial infarction with quality and outcomes. J Am Med Assoc 2009; 302(20): 2207-13.

15. Subbana V, Lakshmananb A, Victora SM, Pakshirajana B. Outcome of primary PCI e An Indian tertiary care center experience. Indian Heart J 2014; 66(1): 25-30.

16. Kırma C, Oduncu V, Tanalp AC, Erkol A. Primary angioplasty in a high-volume tertiary center in Turkey: in-hospital clinical outcomes of 1625 patients. Arch Turk Soc Cardiol 2011; 39(4): 300-07.

17. Diletti1 R, Yetginl T, Manintveld1 O. Percutaneous coronary interventions during ST-segment elevation myocardial infarction: current status and future perspectives. Euro Intervention
2014; 10(1): T13-22.

18. Keeley EC, Hillis LD. Primary PCI for myocardial infarction with ST-segment elevation. N Engl J Med 2007; 356: 47-54.

19. Laarman GJ, Suttorp MJ, Dirksen MT, van Heerebeek L, Kiemeneij F, Slagboom T, et al. Paclitaxel- eluting versus uncoated stents in primary percutaneous coronary intervention. $\mathrm{N}$ Engl J Med. 2006; 355(11): 1105-13.

20. Iakovou I, Schmidt T, Bonizzoni E, Ge L, Sangiorgi GM, Stankovic G, et al. Incidence, predictors, and outcome of thrombosis after successful implantation of drug-eluting stents. J Am Med Assoc 2005; 293(17): 2126-30.

21. Hiroshi I. No-reflow phenomenon and prognosis in patients with acute myocardial infarction. Nat Clin Pract Cardiovas-cular Med 2006; 3(1): 499-506.

22. Berger PB, Ellis SG, Holmes DR, Granger CB, Criger DA, Betriu A, et al. Relationship between delay in performing direct coronary angioplasty and early clinical outcome in patients with acute myocardial infarction: results from the global use of strategies to open occluded arteries in Acute Coronary Syndromes (GUSTO -IIb) trial. Circulation 1999; 100(1): 14-20. 